\title{
Vive la difference
}

People, it would appear, need to have a reason for spending more money that makes sense in their terms, and some people value paying for the non-clinical aspects of their care

\begin{abstract}
magine a situation where you are buying a new washing machine. In the showroom you see a range of machines, and you ask the salesman what the difference is between the more expensive ones and the cheaper ones. He replies that there is no difference at all, but the more expensive ones took longer to construct.
\end{abstract}

On the assumption you believed him it is unlikely you would choose to buy the more expensive machine. Why should you, if they are all exactly the same apart from the fact that the manufacturing process was slower in the factory? While this type of situation is obviously ridiculous, from a patient's point of view it makes as much sense as being told that the difference between private and NHS dentistry is that the dentist will take more time if you are a private patient (in other words work more slowly).

Before people start insisting that dentistry and washing machines are completely different (after all, one is a product and one a service) we need to remember that I am looking at this from the patient's viewpoint. After all, asking what the difference is between NHS and private dentistry is not an unreasonable question for a patient to ask. If we were to ask the equivalent question ourselves in a similar situation then we would expect an answer that made sense to us. Yet when a patient asks it can cause some difficulty in providing a valid answer that does make sense to the patient.

Why should it be so difficult? Perhaps it is because there actually is no difference. Perhaps it is because people dislike having to talk about money or to 'sell'. Often behind it is the concern over the NHS regulations which currently prevent people from implying that NHS dentistry is inferior to private dentistry, whatever that may mean.

The real reason people tend to find this topic difficult (in my opinion) is the fact that the answers usually revolve around the clinical treatment provided, as if this is where the difference should lie. Yet many people purchase private medicine without worrying about the fact that doctors will probably take as long to perform operations or make a diagnosis whether you are a private patient or an NHS one, or that surgeons will use the same quality of scalpel blade or suture regardless of the patient's choice of payment. As for the idea that a private operation will 'take more time' I would imagine that would raise concern from everyone involved. People buy private medicine for convenience, choice of doctor (in some cases), choice of time to be seen and treated, status and level of care in arranging the visits (contacting reception, etc).

Perhaps dentists can learn something from the two examples of buying a consumer item or seeking private medicine. People, it would appear, need to have a reason for spending more money that makes sense in their terms, and some people value paying for the non-clinical aspects of their care. The other main point is that there must be a definite difference in benefits between differently priced options for people to feel it is worth paying the extra.

However, I cannot help but feel that the real problem is that many dentists still find it difficult to put a true value on themselves and their services. As a consequence they believe that patients do not really want to buy what they (the dentists) have to sell. In other words they believe the constant perception that dentistry is still something no-one wants. This perception continues to bombard us all, from advertisements, jokes, stories in the press and subtle inferences in daily conversation. While the mood is slowly changing we must, as a profession, demonstrate our own belief in ourselves by not being afraid to ask for an appropriate fee for added value in our private dentistry. Before we can do that however,

Mike Grace we must be sure that there are genuine added benefits for private patients in terms they understand and are prepared to pay for. Otherwise no-one wins. 